\title{
Slow Quasi-Periodic Curves and Spiral Cracks in Chalcogenide Glass Thin Films
}

\author{
Myroslav Kozak ${ }^{1}$, Vladimir Zhikharev ${ }^{1}$, Vasyl Loya ${ }^{2}$ and Vasyl Fedelesh ${ }^{1}$ \\ 1. Faculty of Physics, Uzhhorod National University, Uzhhorod 88000, Ukraine \\ 2. Institute of Electron Physics, Uzhhorod 88000, Ukraine
}

\begin{abstract}
In the paper, thin films $(1.5 \div 2.5 \mu \mathrm{m}$ thick $)$ of $\mathrm{As}_{2} \mathrm{~S}_{3}$ and $\mathrm{As}_{2} \mathrm{Se}_{3}$ chalcogenide glasses were investigated. The propagation of slow curves cracks in real time was observed, as well as circular Hertz cracks, the growth of which is an increase in the diameter of the crack in time. All crack patterns known in the literature were observed. Research shows the spiral crack is a consequence of the superposition of the Hertz crack and the straight crack. The principle of coordination of stress relieving during the formation of patterns is formulated. Authors have done a lot of research work. And authors have drawn some meaningful conclusions.
\end{abstract}

Key words: Chalcogenide glasses, crack patterns, spiral crack, Hertz crack.

\section{Introduction}

We are somewhat lucky. Studying the optical properties of thin films of chalcogenide glasses (primarily $\mathrm{As}_{2} \mathrm{~S}_{3}$ and $\mathrm{As}_{2} \mathrm{Se}_{3}$ ), we performed thermal annealing of these films. As is well known, the quality of annealing depends on the film thickness and annealing conditions. For example, $\mathrm{As}_{2} \mathrm{~S}_{3}$ films are qualitatively annealed in argon and provided that their thickness is less than one micron. Upon annealing of films with a thickness of about $2 \mu \mathrm{m}$ in air, we observed cracking of the films. Moreover, the most diverse cracking patterns were observed, including spiral and sawtooth cracks [1]. A systematic study of cracking in thin films of chalcogenide glasses yielded a number of results, which will be presented in this paper.

\section{Experiment and Experimental Results}

Thermally deposited films in vacuum, we annealed in two modes. In the first case, in the oven, we heated the films from room temperature to glass transition

Corresponding author: Myroslav Kozak, Dr., research fields: optics, mechanics. temperature $T_{\mathrm{g}}$ (about $180{ }^{\circ} \mathrm{C}$ ) at a rate of $0.3{ }^{\circ} \mathrm{C} / \mathrm{s}$, held for 30 minutes and allowed the films with the oven to cool to room temperature. Note that the film thickness should be chosen $2 \mu \mathrm{m}$ or more, because, for example, at a thickness of $1 \mu \mathrm{m}$ annealing will be without cracking (such films are used in optical research). In this way, we obtained patterns of so-called mud cracks (Fig. 1). For comparison, we show a picture from the pioneering work of Kindle [2] (Fig. 2), whence it is clear that the name "mud cracks" is quite legal for patterns in thin films. The second mode of annealing is quite simple, but it provides the opportunity to obtain unusual patterns and observe slow solitary cracks. It lies in the fact that the sample is heated at the same speed and when the glass transition temperature $T_{\mathrm{g}}$ is reached, it is immediately placed on the table of the optical microscope. In this case, the sample is continuously but quickly cooled. At a temperature of about $80^{\circ} \mathrm{C}$, the process of crack propagation begins, which does not stop up to room temperature and even after it has been reached for another 5-10 hours. In this mode, even mud cracks may already be unusual, for example, as shown in Fig. 3 , they may consist of almost straight elements. 


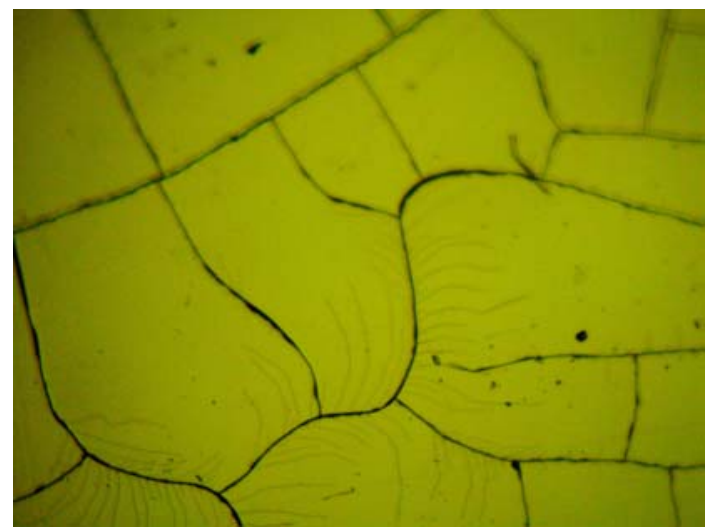

Fig. 1 Image in an optical microscope (magnification $\times 200$ ) of mud cracks in an $\mathrm{As}_{2} \mathrm{~S}_{3}$ film $2 \mu \mathrm{m}$ thick on a Pyrex glass substrate with dimensions of $30 \times 25 \times 3 \mathrm{~mm}^{3}$.

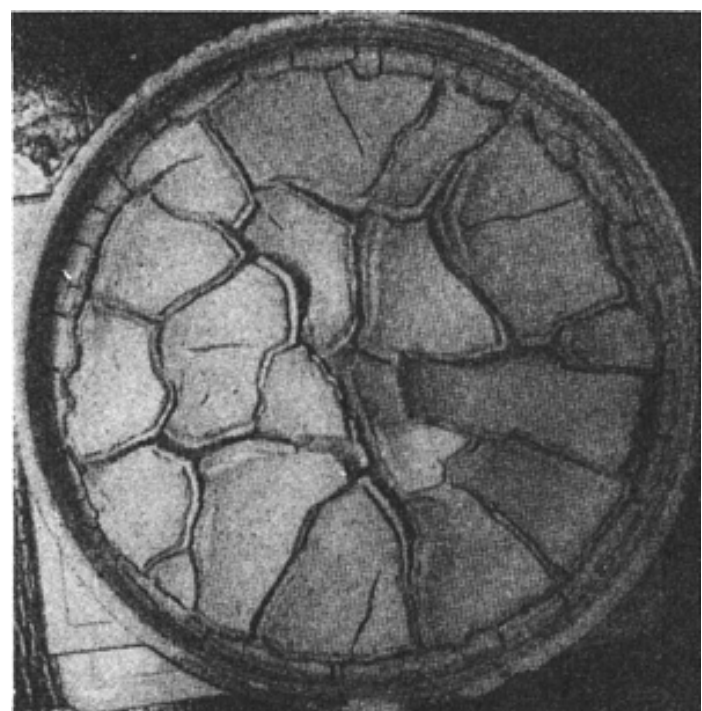

Fig. 2 Pattern on the surface of dried clean clay from the bottom of Lake Ontario. The real size of the vessel is 4 times larger.

Source: the work of Kindle [2].

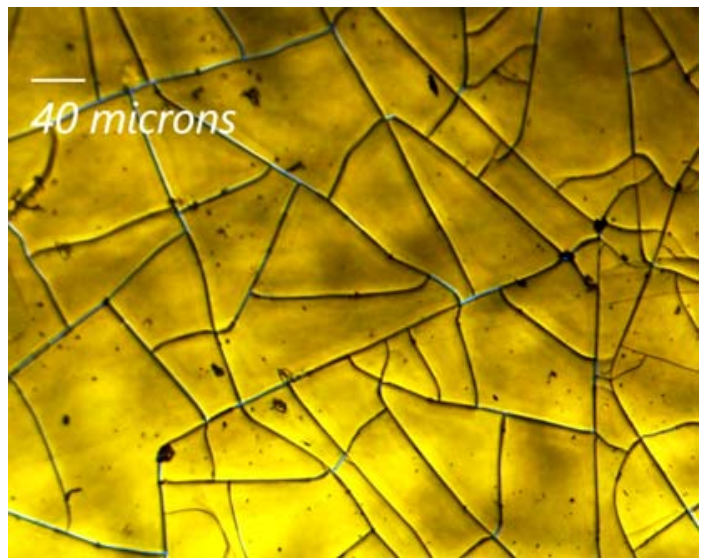

Fig. 3 Photograph of the pattern with almost straight elements.

However, it was unexpected that mud patterns could be formed from sinusoidal curves (Fig. 4). As shown in Ref. [3], thin plates of glass during quenching can crack along straight or sinusoidal lines. 
We got an excellent agreement with this work. Further more interesting, the quasiperiodic elements of the patterns can be formed from fragments of a spiral (Fig. 5).

Such sawtooth patterns in Ref. [4] are given under the romantic name "alley of crescents", but this is just a spiral that, for reasons unknown so far, changes its orientation from time to time. However, under appropriate conditions, apparently with a sufficiently uniform stress field, the spiral crack curve does not change orientation, and we observe a helix of several turns. This may be a somewhat imperfect spiral, as shown

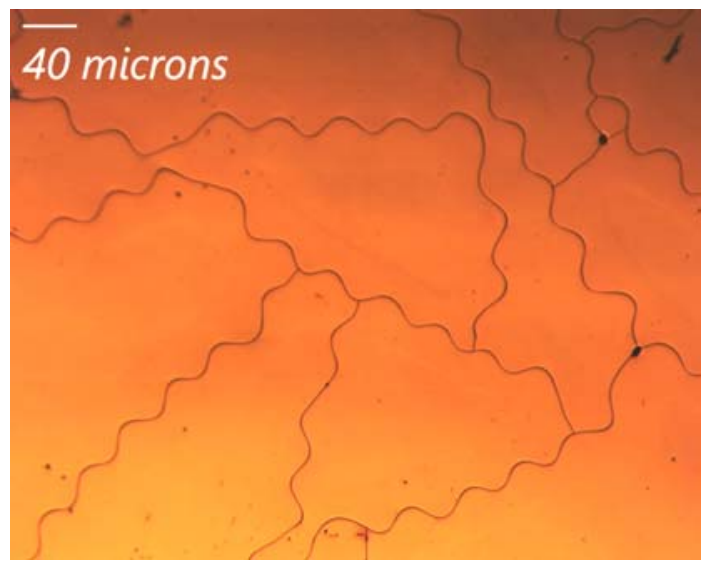

Fig. 4 Photograph of a film with a sinusoidal pattern.

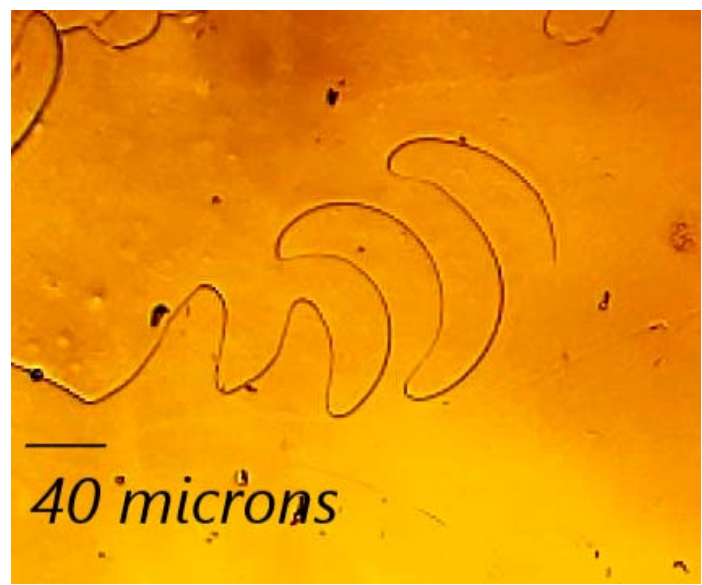

(a)

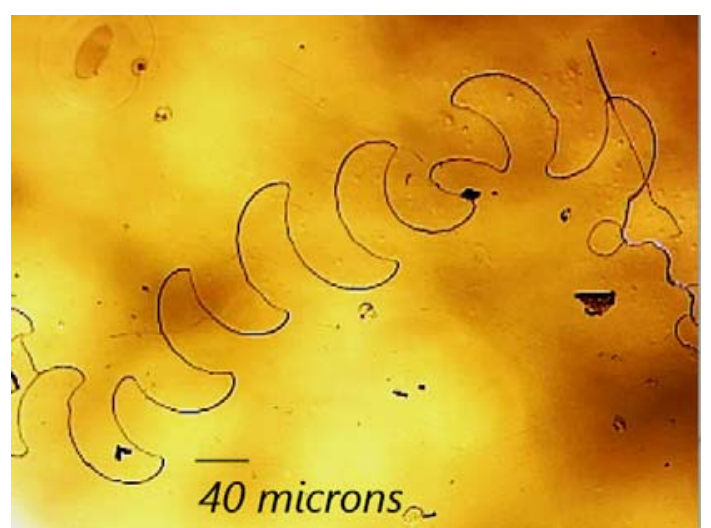

(b)

Fig. 5 Quasi-periodic sawtooth-like (unwrapped spiral) patterns: (a) solitary crack and (b) crack in the filamentous network. 


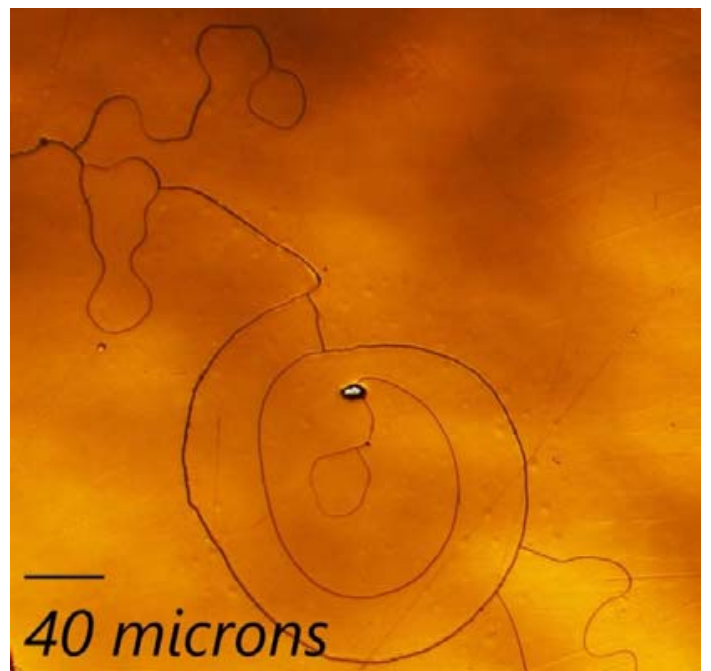

(a)

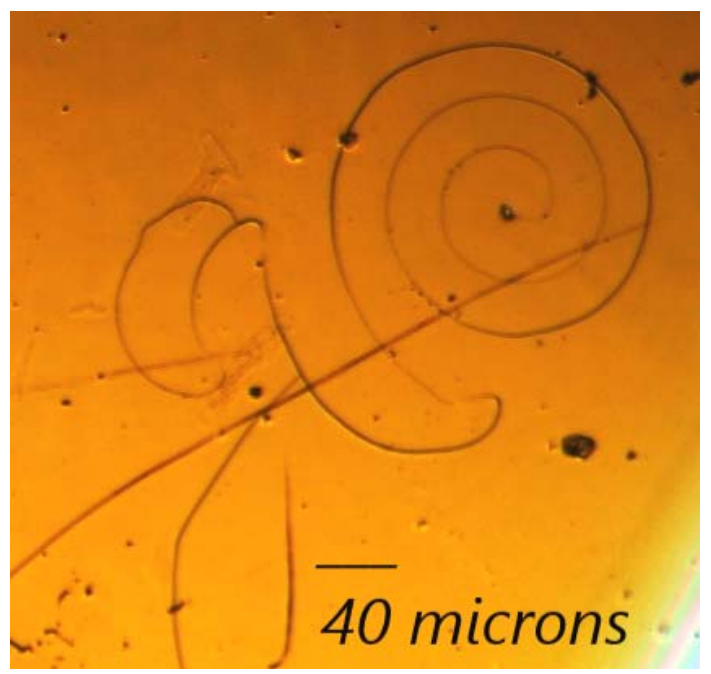

(b)

Fig. 6 Photos of spiral cracks in the $\mathrm{As}_{2} \mathrm{~S}_{3}$ film: (a) imperfect right spiral and (b) perfect left spiral.

in Fig. 6a, or an ideal spiral in Fig. 6b.

The picture shown in Fig. $6 b$ one to one was observed in Ref. [5], where cracks in $\mathrm{Mo} / \mathrm{Si}$ multilayers were also studied under thermal load. Known and earlier publications on the observation of spiral cracks are Ref. [6], where spirals were observed in polymer films, Ref. [7] in sol-gel coatings, Ref. [8] in layers of asphalt, Ref. [9] in drying precipitates and also Ref. [10], apparently the first work, which shows photographs of spiral cracks on etched glass surface. The formation of cracks in thin films of chalcogenide glass occurs at an extremely low speed compared with the speed of a crack in silicate glass, which is, as is well known, about $1,500 \mathrm{~m} / \mathrm{s}$ [11], especially slow solitary curvilinear cracks, which we will demonstrate. The speed of such a crack is easily determined using ordinary video. Fig. 7 shows a sequence of frames from such a video. Even from the induced frames, one can judge about a certain average crack velocity. Paying attention to the scale of images, we see that it is tens of microns per second. However, a closer look at the process on the video shows that the crack velocity is not very constant. The process looks like there is a "pumping" with a very slow increase in the length of cracks, and then they, like predators, make jerks, which is extremely impressive. It should be noted, we are dealing with a highly non-linear process. The sample temperature is constantly decreasing, 
which leads to an increase in stress. In addition, the elongation of cracks in different areas makes changes in the stress field. Anyway, we see a wonderful demonstration of the confirmation of the Griffith theory. So far, we have used only $\mathrm{As}_{2} \mathrm{~S}_{3}$ films. It turns out that the composition of this glass is modified by some chemical elements, for example zinc, which we used, as well as the composition $\mathrm{As}_{2} \mathrm{Se}_{3}$ can demonstrate a fundamentally new type of patterns. These patterns may include Hertz cracks, i.e. circular cracks [12]. Fig. 8 shows how a Hertz crack is extended; it is extended by increasing its radius.

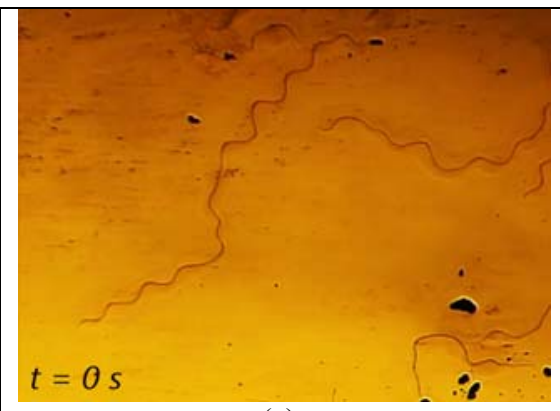

(a)

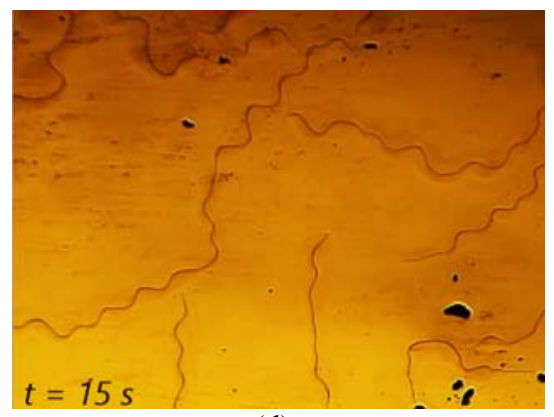

(d)

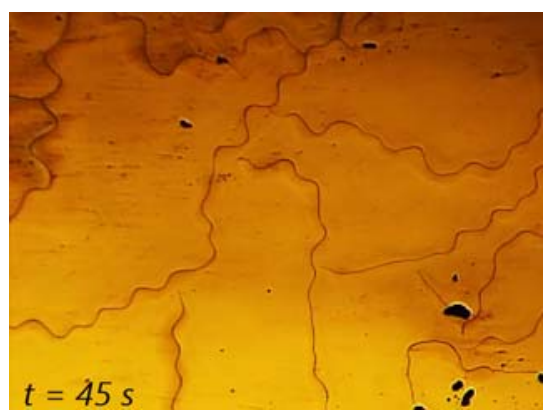

(g)

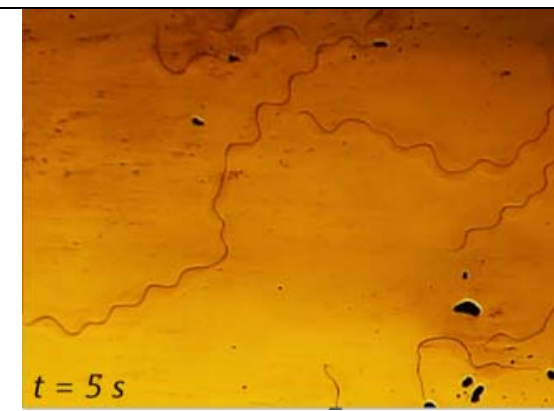

(b)

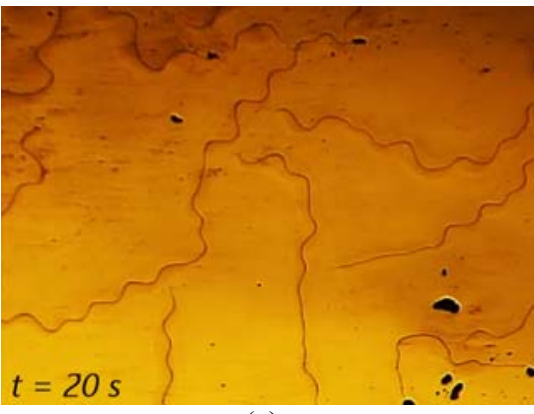

(e)

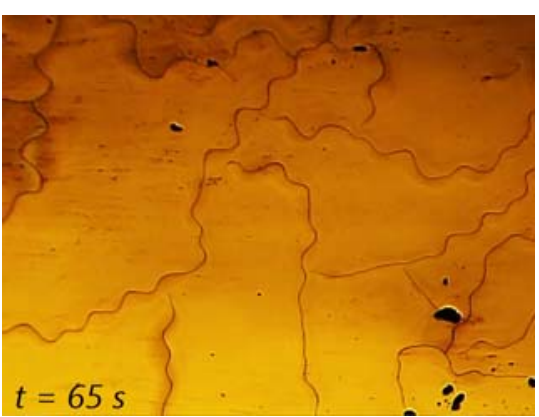

(h)

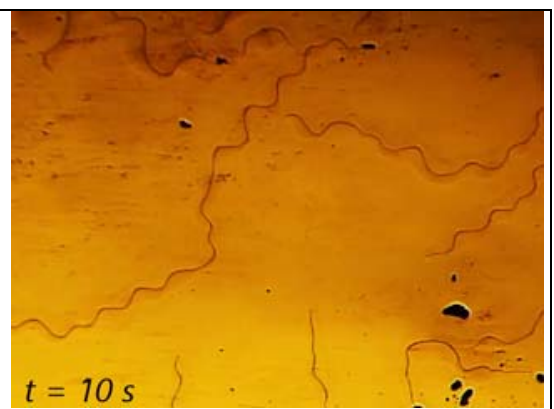

(c)

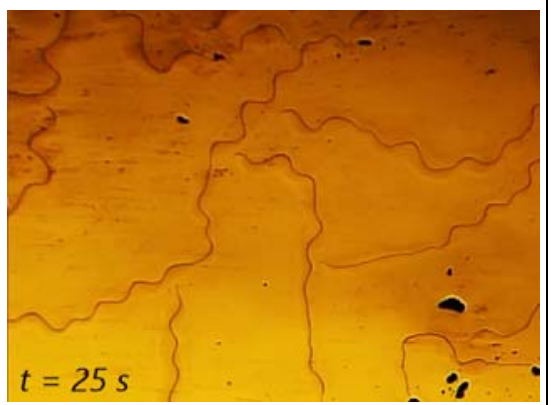

(f)

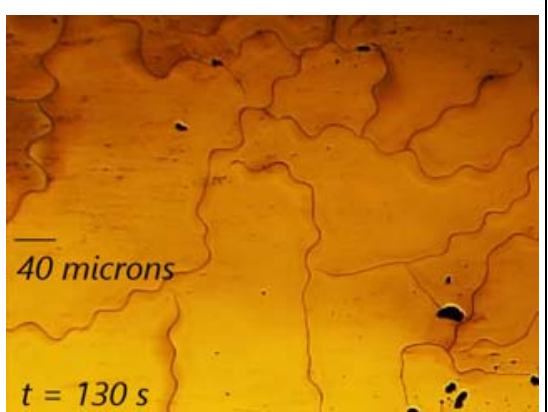

(i)

Fig. 7 Separate frames from the video of the propagation of a curved crack in a thin film with an indication of the relative recording time $t$. 


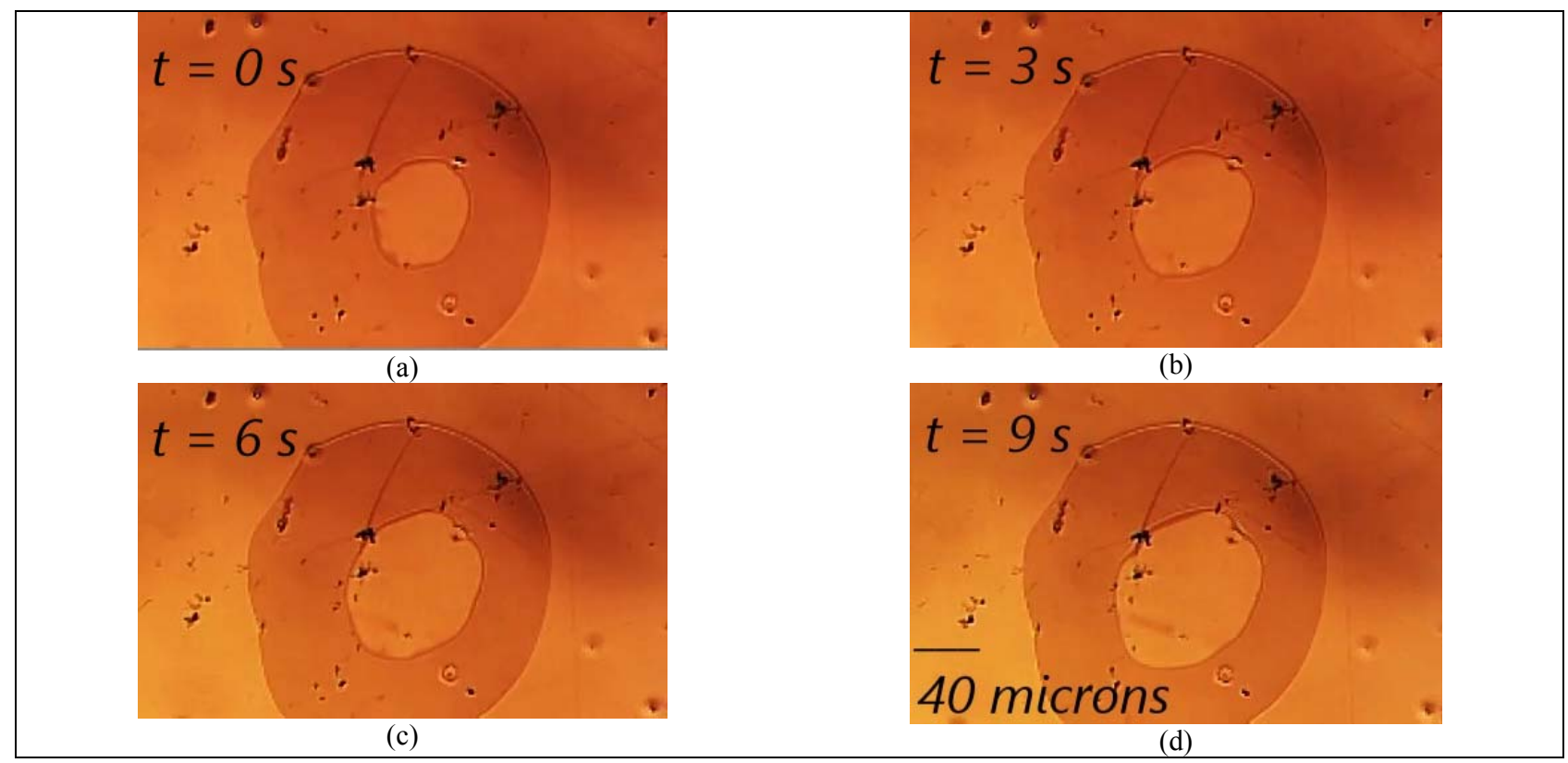

Fig. 8 Separate frames from the video recording of the process of lengthening the Hertz's crack in a thin film of composition $\mathrm{As}_{2} \mathrm{~S}_{3} / \mathrm{Zn}$ (zinc content 2 at.\%).

\section{Discussion and Conclusions}

Observation of this last fact is of great importance for understanding the mechanism of the formation of a spiral crack. Now we can state that a spiral crack is a superposition of a curvilinear extended crack and a Hertz's crack. It is believed that the spiral cracks are described by the spiral of Archimedes. By definition, the Archimedes spiral is a curve that is described by a point of a beam moving at a constant speed from the beginning of the beam along it, while the beam rotates around its origin with a constant angular velocity. A more precisely and physically clear spiral crack is described by an involute of a circle, which is very similar to the Archimedes spiral. The circle in our case is the area of detachment, which creates a crack as a defect according to the Griffith theory. This is clearly seen in Fig. 6. The remarkable property of an involute is that the normal at any point of it is tangent to a circle. From this follows, as we shall call, the principle of stress matching, which is as follows. Any crack propagating relieves stress along the normal to the direction of its propagation. A crack-causing defect area, if it is considered a circle, relieves stress in radial directions. Thus, some spiral normal is tangent to the circle, and therefore perpendicular to the radial ray of the circle. This is the principle of stress relieving. Based on this principle, it is easy to explain the fact that in the mud patterns the crack connects with another (curved) crack from the convexity side at the point of the greatest curvature at a right angle. In demonstrating Fig. 1, we ignored its features. In the lower part of the figure, besides the main cracks, we also see a pre-crack of very small width. Due to the fact that we were able to capture this image, it becomes clear the distribution of stresses along the crack curve. Near the apex, the pre-crack curvatures are formed normally from the bulge side. They relieve stress tangential to the crack. From the side of the concavity, the pre-crack is parallel to the main crack; the other crack does not join from the side of the concavity. In conclusion, we note that measurements and video registration on a real time scale of the process of crack propagation in thin films open up new possibilities for the development of the theory of fracture mechanics as a whole.

\section{References}

[1] Kozak, M. I., Zhikharev, V. N., Fedelesh, V. I., Solomon, A. M., and Loya, V. Y. 2018. "Photoinduced, 
Thermo-reversible and Irreversible Transformations, and Accompanying Mechanical Transformations in Thin $\mathrm{As}_{2} \mathrm{~S}_{3}$ Glass Films." OSA Thech. Digest, Paper JTu2A.26. https://doi.org/10.1364/BGPPM.2018.JTu2A.26.

[2] Kindle, E. M. 1917. "Some Factors Effecting the Development of Mud-Cracks." J. Geol. 25: 135-44.

[3] Yuse, A., and Sano, M. 1993. "Transition between Crack Patterns in Quenched Glass Plates." Nature 362: 329-31.

[4] Marthelot, J., Roman, B., Bico, J., Teisseire, J., Dalmas, D., and Melo, F. 2014. "Self-replicating Cracks: A Collaborative Fracture Mode in Thin Films." Phys. Rev. Lett. 113: 085502.

[5] Kravchenko, G., Tran, H. T., and Volinsky, A. A. 2018. "Periodic Cracks and Temperature-Dependent Stress in Mo/Si Multilayers on Si Substrates." Phil. Mag. 98 (19): 1765-79.

[6] Macnulty, B. J. 1971. "Spiral and Other Crazing and
Cracking in Polymers with Phenilene Groups in the Main Chain." J. Mater. Sci. 6: 1070-5.

[7] Sendova, M., and Willis, K. 2003. "Spiral and Curved Periodic Crack Patterns in Sol-Gel Films." Appl. Phys. A 76: 957-9.

[8] Behnia, B., Buttlar, W. G., and Reis, H. 2017. "Spiral Cracking Pattern in Asphalt Materials." Mater. Design 116: 609-15.

[9] Leung, K.-T., Józsa, L., Ravasz, M., and Néda, Z. 2001. "Spiral Cracks without Twisting." Nature 410: 166.

[10] Argon, A. S. 1959. "Surface Cracks in Glass." Proc. $R$. Soc. Lond. 250: 472-81.

[11] Barstow, F. E., and Edgerton, H. E. 1940. "Glass-Fracture Velocity." J. Am. Cer. Soc. 22: 302-7.

[12] Ball, A., and McKenzie, H. W. 1994. "On the Low Velocity Impact Behavior of Glass Plates." J. de Phys. IV 4: 783-8. 